\title{
La situación económica de la Argentina
}

\section{The economic situation of the Argentina}

\section{Alfredo Eric Calcagno}

École Nationale d'Administration, actualmente es diputado

Nacional de Buenos Aires,

Argentina.

«ericcalcagnoq@yahoo.com»

Journal of Economic Literature (JEL):

F, N26, 057

Palabras clave:

Economía internacional

América Latina

Estudios comparativos de países

Keywords:

International Economics

Latin America

Comparative Studies of Countries

\section{Resumen}

Argentina aplica un modelo de desarrollo económico con inclusión social y en doce años se han mejorado sensiblemente los principales indicadores económicos, como resultados de 31 acciones de gobierno aplicados de 2003 a la fecha. En la raíz de la actual crisis global destacan tres problemas básicos: cómo desbaratar la hegemonía del sector financiero globalizado y de sus agentes locales; cómo restablecer la potestad soberana del Estado para cumplir con su rol histórico de impulsar un desarrollo incluyente y sostenible; y cómo redistribuir la riqueza, el conocimiento para dar sustento económico, político y social a ese proceso. Se advierte que las conquistas obtenidas hacen muy difícil un retroceso; pero aun cuando así fuera, la política económica neoliberal no podrá exhibirse más como la única posible.

\section{Abstract}

Argentina applies a model of economic developing with social inclusion and in twelve years the principal financial indicators have improved noticeably, as a result of 31 actions of government applied since 2003 to date. In the root of actual global crisis highlight three basic problems: how to disrupt the hegemony of the globalized financial sector and its local agents; how to reestablish the sovereign power of the State to fulfill its historic role of promoting inclusive and sustainable development; and how toreallocate wealth, the knowledge to give economic, political and social sustenance to that process. One warns that the obtained conquests make avery difficult setback; but even if so, neo-liberal economic policy may not be more exhibit as the only possible. 
Desde 2003 se aplica en la Argentina un modelo de desarrollo económico con inclusión social, diametralmente opuesto al que impone el Fondo Monetario Internacional. Desde entonces, en doce años se han duplicado el producto interno bruto, la inversión fija bruta y el producto generado por la industria (todo en \% del PIB); se triplicaron las exportaciones; la deuda pública externa se redujo de 95 a 11.6\% del PIB; la desocupación cayó de 21 a 7\%; la participación de los asalariados en el ingreso se elevó de 34 a 51\%. Y así ocurrió en casi todos los temas. Estas cifras no son las de proyecciones de planes hipotéticos, sino los resultados logrados en ese período; a lo largo del artículo se especifican 31 de los principales actos de gobierno realizados para obtenerlos.

Queda claro que este artículo no propone la aplicación de esa política

La política económica a otros países; son sus pueblos y dirigentes quienes tienen que económica resolverlas. Sin embargo, en la raíz de la crisis global actual existen tres neoliberal no podrá problemas básicos: cómo desbaratar la hegemonía del sector financiero exhibirse más como globalizado y de sus agentes locales; cómo restablecer la potestad sobela única opción rana del Estado para cumplir con su rol histórico de impulsar un desarrollo posible incluyente y sostenible; y cómo redistribuir la riqueza, el conocimiento y la palabra para dar el sustento económico, político y social a ese proceso.

Las conquistas obtenidas hacen muy difícil un retroceso; pero aun cuando así fuera, la política económica neoliberal no podrá exhibirse más como la única opción posible, pues la experiencia argentina nos muestra alternativas viables.

En su artículo sobre Los rezagos de la política social, 1 David Ibarra plantea medidas fundamentales para el mejor funcionamiento de las sociedades contemporáneas: frenar los excesos de los mercados, redistribuir ingresos y devolver poder ordenador a los Estados. "Sacar de la hibernación a la democracia global y de los países es un imperativo categórico, aun siendo desiderátum utópico mientras subsista el dominio de los paradigmas neoliberales. El cambio llegará tarde o temprano vía la acción humana, al persistir y aún ahondarse las fallas estructurales del mundo, que a la postre obligarán a cambiar los paradigmas la protección social” (p. 49). Sobre la base de su análisis profundo y pertinente, el doctor lbarra resume su pensamiento: "se presentan algunas ideas de cambio de políticas, aunque todavía se esté lejos de la formulación de nuevos paradigmas sobre el orden socio-político universal y del interno delos países. Con todo, ya va siendo hora de comenzar a plantear alternativas frente a desigualdades en ascenso y una crisis mundial casi interminable" (p. 26).

Creo que este artículo del doctor lbarra representa un desafío y constituye un programa de trabajo, que requiere el análisis del panorama internacional y de la si-

Revista EConomíaunam, vol. 11, núm. 33, México, septiembre de 2014. 
tuación de varios países. Es una circunstancia que tiene pasado, presente y futuro, que deberán estudiarse para diseñar opciones. Por eso, como un aporte a esa dura, creativa y larga tarea, voy a describir lo ocurrido en la Argentina en el período 20032015, que constituye una alternativa aplicada durante 12 años. Allí se muestra que no es cierto que la única solución para salir de una crisis económica y financiera sea el ajuste recesivo exigido por el Fondo Monetario Internacional (FMI); y que de una crisis causada, primero por la creciente hegemonía del sector financiero globalizado; segundo, por la reducción del rol del Estado; y tercero, por la creciente desigualdad, no se sale con más neoliberalismo.

Tampoco es cierto que el programa argentino sea la única alternativa. Cada país tiene sus particularidades, que van desde su historia, hasta la mentalidad de sus habitantes y las relaciones de fuerza entre las agrupaciones políticas y económicas. Es evidente que los procesos de cambios profundos no son exportables; pero sí es bueno saber qué le ocurrió a otros países, para afinar las propias estrategias y tácticas. En ese sentido, la experiencia latinoamericana es riquísima, porque confluyeron situaciones muy difíciles, con pueblos politizados y algunos líderes excepcionales: por ejemplo, Hugo Chávez (1999); Lula Da Silva (2003); Néstor y Cristina Kirchner (2003 y 2007); Evo Morales (2005); Rafael Correa (2007). Cada uno de esos gobiernos y pueblos realizaron como pudieron su lucha por la soberanía nacional, la democracia política, el desarrollo económico y la inclusión social. Deberán estudiarse y evaluarse sus logros y retrocesos, sus éxitos y fracasos; pero en un primer balance es evidente que existió un saldo muy favorable en la recuperación de la soberanía nacional, en el crecimiento económico y en la inclusión social.

En este breve trabajo, sintetizaré la experiencia argentina en el período 20032015, tal cual la viví. Como soy argentino, corresponde que le diga al lector mexicano desde qué posición ideológica y política escribo. En mi caso, no soy un observador independiente, incoloro, inodoro e insípido, sino un militante político desde el principio de la adolescencia hasta mis actuales 90 años. Siempre he mantenido mi orientación nacional y popular, y rechazado los paradigmas reaccionarios y neoliberales, que cambiaron de nombre según las épocas.

\section{Los principios básicos aplicados}

El relato de lo ocurrido en la Argentina puede interesar a nivel internacional,

porque es un ejemplo típico de una política económica exitosa, que está en las antípodas del pensamiento neoliberal, en especial de las recetas del FMI. Donde fracasó la política del FMI y sus socios locales aplicada durante 25 años, triunfó una política heterodoxa practicada durante 12 años (que continúa), que está basada en la soberanía nacional, la inclusión social, la democracia política y el desarrollo sobre la base de recursos y financiamiento propios.

La experiencia de gobierno en la Argentina desde 2003, ha sido ignorada o falseada por la prensa hegemónica nacional y mundial, por lo que es necesario comenzar por el relato de los hechos ocurridos.

A continuación reseñaré los principios básicos de la obra de gobierno. Este relato no se refiere a los hechos deseados, sino a los cumplidos; las cifras no son de 
proyecciones, sino que dan cuenta de los resultados. Abarca un período de tiempo lo suficientemente extenso -12 años- como para extraer conclusiones acerca de lo ocurrido.

No se aplicó un esquema teórico global a una realidad coherente y prevista, sino que se gobernó en una situación inicial caótica, que se fue transformando en el tiempo: la Argentina de 2015 es muy diferente a la del 2003. No existió un plan económico clásico sino el enfrentamiento cotidiano con la necesidad de gobernar sobre la base de algunas pocas ideas básicas coherentes, de carácter político. Se fue rescatando así un Proyecto Nacional que se basa en la recuperación de la soberanía nacional y de la soberanía popular, y que tiene como ejes el desarrollo económico con inclusión social y la recuperación de la hegemonía de los sectores productivos frente a los financieros.

En este caso, lo importante es saber cuáles eran -y siguen siendo- esos principios; y es fundamental poder decir "y siguen siendo" porque una característica nefasta de muchos partidos políticos una vez llegados al poder, fue el cambio de objetivos y, sobre todo, de grupos sociales y económicos beneficiados. En el caso de los gobiernos Kirchner, los principios básicos se mantuvieron durante todo el período.

Como se trata de políticas de largo plazo, existe un pasado, un presente y un futuro.

\section{El pasado}

En los últimos 130 años existieron en la Argentina varios períodos históricos y cada uno representó una modalidad de desarrollo. A grandes rasgos, pueden distinguirse la Argentina agraria (18801945), la industrial (1946-1975), la de renta y financiera (1976-2001) y por último la de desarrollo con inclusión social, que se va construyendo desde 2003.

En 1976, la Argentina industrial fue reemplazada, con violencia, por el La Argentina modelo neoliberal de renta y financiero, que rigió hasta el derrumbe de la industrial fue convertibilidad a principios de 2002. Sus principales características fueron: reemplazada, por el endeudamiento externo, dependencia de Estados Unidos, redistribución modelo neoliberal a de ingresos adversa a los asalariados, liberalización del sistema financiero, principios de 2002 apertura externa comercial y financiera, política antiinflacionaria basada en la sobrevaluación de la moneda nacional, privatizaciones generalizadas (a partir de 1990) y restricción de la demanda popular. Algunos de sus resultados se muestran en el cuadro 1.

$\begin{array}{lrr} & 1976 & 2002 \\ \text { PIB por habitante (1976=100) } & 100 & 88 \\ \text { \% de la industria en el PIB } & 33 & 15 \\ \text { Pobres (\% de la población) } & 4,7 & 54,3 \\ \text { Desocupados (\% de la población económicamente activa) } & 4,5 & 17,8\end{array}$

Fuente: Instituto Nacional de Estadística y Censos (INDEC). 
En 2002, la Argentina estaba en el peor de los mundos posibles, con grave riesgo de disolución nacional, con 14 monedas provinciales, los depósitos bancarios bloqueados y dependencia total del FMI, que ya estaba instrumentando la dolarización. ${ }^{2}$ Esta fue la situación política, social y económica que provocó el modelo de renta y financiero, que destruyó gran parte del sistema productivo, devastó la industria, dilapidó el patrimonio nacional, multiplicó la desocupación, deprimió los salarios reales, redujo la inversión, deterioró los servicios públicos, sobreendeudó al Estado y produjo profundas crisis financieras que cerraron el crédito externo.

Los resultados económicos de los cuatro períodos, medidos por el producto interno bruto (PIB) por habitante, muestran que la Argentina agraria (1880-1945) creció a 1.3\% anual; la industrial (1946-1975) a 2.1\%; la rentístico financiera (1976-2002), decreció a -0.2\% anual; y la de desarrollo con inclusión social (desde 2003) creció a $6 \%$ anual. Entre 1976 y 2002 (26 años), el PIB por habitante se redujo de 8000 a 7200 dólares; y entre 2002 y 2014 (12 años), aumentó de 7200 a 13200 dólares (los dólares son internacionales, calculados por Maddison a precios de 1990). ${ }^{3}$

El quiebre del crecimiento se produjo a partir de 1976, durante el

Bajo el régimen modelo neoliberal, y culminó en 2001-2002. No sólo cayó el monto del neoliberal de renta PIB por habitante, sino que se degradó su composición y distribución. y financiero, la En la gráfica se observa cómo en ese período aumentó de modo susArgentina retrocedió cuando la mayoría de los países crecía tancial el PIB por habitante de los otros países considerados, en especial de los desarrollados. Ahí nos quedamos muy atrás (véase la gráfica 1).

Desde 1870 hasta 1976 prevaleció una economía de producción -ya sea agraria o industrial-, y la Argentina creció a tasas razonables. La gráfica 1 muestra cómo el quiebre del crecimiento argentino se produjo entre 1976 y 2002, cuando el sector financiero pasó a regir la economía y entonces el motor de la actividad dejó de ser la producción (agraria e industrial) y fue el endeudamiento externo (era más barato importar que producir). En ese período, bajo el régimen neoliberal de renta y financiero, la Argentina retrocedió cuando la mayoría de los países crecía a tasas aceleradas.

Este régimen fue sostenido por el sector financiero, las empresas transnacionales y los empresarios nacionales grandes; además, contó con la aquiescencia de una parte de la "mayoría silenciosa" que pudo viajar y comprar productos importados gracias al dólar barato (en lenguaje popular, la "plata dulce") y que quiso ignorar -e ignoró- la desaparición masiva de personas (y también de las empresas públicas).

Fondo Monetario Internacional, Oficina de Evaluación Independiente, The FMI and Argentina. 1991-2001, Washington DC, 2004.

Angus Maddison, L'économie mondiale. Une perspective millénaire, OCDE, París, 2002. No es arbitrario tomar los datos de 2002, porque fue el año en que la crisis del modelo anterior tocó fondo y porque dos terceras partes de la contracción del PIB de ese año (-10,9\%) corresponden al arrastre estadístico negativo del último año de la convertibilidad. 


\section{Gráfica 1}

PIB por habitante de países seleccionados, 1870-2013

(en dólares internacionales

de 1990)

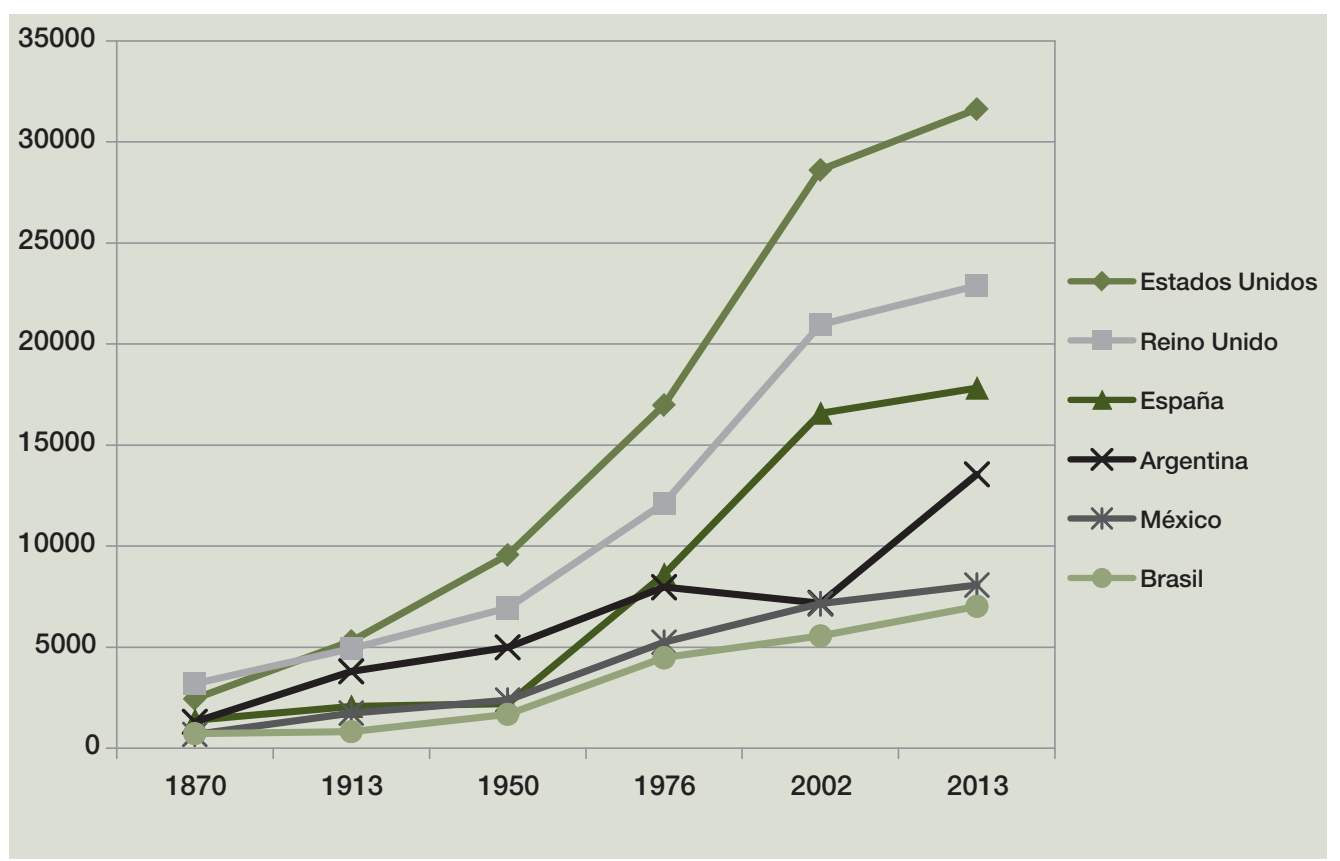

Fuente: Para el PIB hasta 1998, A. Maddison, L'économie mondiale, Paris, OCDE, 2002. Para 2002 y 2013 se aplicaron tasas de crecimiento de UNCTAD, Trade and Development Report, Nueva York y Ginebra, 2014.

\section{El derrumbe del neoliberalismo}

2003. Los 40 millones de argentinos (en números redondos) vivían de modo muy desigual. Los que estaban más arriba en la escala social, eran 3 millones de habitantes, con alta calidad de vida. Los 7 millones ubicados inmediatamente por debajo de ellos, tenían un buen pasar. Le seguían 10 millones de personas, que correspondían a una antigua clase media crecientemente pauperizada, pero que se ilusionaban con compartir algunos consumos de los grupos privilegiados. Entre todos, sumaban cerca de la mitad de la población; pero la otra mitad estaba formada por 20 millones de personas que padecían algunas formas de exclusión económica o social. Había $46 \%$ de pobres (que incluía $19 \%$ de indigentes), $22 \%$ estaba desocupado y un tercio de la población carecía de seguridad social.

Con este panorama, el Estado podía aplicar una política de inclusión social o mantener la exclusión. Durante el régimen militar (1976-1983) y el neoliberalismo ortodoxo (1989-2001), las políticas aplicadas ampliaron la desigual distribución del ingreso y de la riqueza; para eso, se utilizó la represión que incluía crímenes de lesa humanidad durante el régimen militar, y la desvirtuación de la conciencia nacional durante el neoliberalismo.

A principios del siglo XXI, había síntomas de disolución nacional: y era indispensable integrar a la Nación a los 20 millones de personas que estaban afuera. Para eso, debía cambiarse la función del Estado. Había una injusta y cruel división entre 
quienes estaban dentro de la sociedad -tenían empleo digno y utilizaban los servicios básicos del Estado (educación, salud, infraestructura) o podían pagar los privados-, y los que quedaban afuera.

\section{Desarrollo económico con inclusión social}

La tarea emprendida desde 2003 se dirigió en lo fundamental a integrar a los 20 millones de excluidos, lo cual era muy difícil porque afectaba la estructura del poder político y económico. Sin embargo, se obtuvieron resultados que nos acercan al Estado de bienestar, como se muestra en el cuadro 2.

\begin{tabular}{|l|r|r|}
\hline Cuadro 2. Argentina: Indicadores socioeconómicos escogidos, 2002 y 2012 \\
\hline Producto interno bruto (millones de pesos de 2004) & 2002 & 2014 \\
\hline PIB por habitante (miles de dólares “internacionales” base 1990) & 451.500 & 873.000 \\
\hline Inversión bruta interna fija (en \% del PIB a precios de 2004) & 7.181 & 13.100 \\
\hline Exportaciones de bienes y servicios (millones de dólares corrientes) & 10,6 & 19,8 \\
\hline Desocupación (en \% de la población activa) & 29.100 & 85.800 \\
\hline Población ocupada en áreas urbanas (miles de personas) & 21,5 & 7,2 \\
\hline Participación de los asalariados en el ingreso (en \%) & 11.182 & 16.097 a/ \\
\hline Cobertura de la seguridad social (en \%) & 34 & 51 a/ \\
\hline Inversión pública (en \% del PIB) & 65 & 96 \\
\hline Presión fiscal (en \% del PIB) & 0,7 & $3,5 b /$ \\
\hline Deuda pública externa (en \% del PIB) & 20 & $31 b /$ \\
\hline
\end{tabular}

Fuentes: INDEC, Ministerio de Economía y Finanzas Públicas, Dirección Nacional de Investigaciones y Análisis Fiscal; y cálculos basados en A. Maddison, Historical Statistics of the World Economy (2003); los dólares "internacionales" establecen una paridad de poder de compra entre los países.

a/ y b/ 2013.

\section{La política económica}

Para poder realizar un programa de desarrollo económico con inclusión social, era necesario generar poder político y recursos económicos. En el plano político, el gobierno recuperó soberanía popular y soberanía nacional. En lo económico, entre 2003 y 2015 se generó soberanía económica y financiera, con el desligamiento del FMI, la reestructuración de la deuda externa y el desendeudamiento externo; se obtuvo soberanía energética con la mayoría estatal en Yacimientos Petrolíferos Fiscales (YPF), la mayor empresa del país, que había sido privatizada en el régimen neoliberal; se reindustrializó la producción; la desocupación bajó del 21,5 a 7.2\%; mejoraron los salarios reales, con la defensa del empleo, las convenciones colectivas de trabajo y los dos aumentos anuales en las jubilaciones. Esto no se logró por las fuerzas del mercado, sino por la acción estatal.

En ese lapso se duplicaron el producto interno bruto (PIB) global, el generado por la industria y las inversiones fijas brutas; a su vez, la deuda pública como porcentaje 
del PIB era una cuarta parte de la de 2002 y la deuda pública externa una séptima parte.

Además existió superávit fiscal primario durante 9 años y financiero durante 7 años. La carga impositiva fue más progresiva: aumentaron los impuestos directos y la presión fiscal (calculada por el Ministerio de Economía y Finanzas Públicas, tomando los ingresos tributarios nacionales, provinciales y de seguridad social) pasó de $22 \%$ del PIB en 2004 a 31\% en 2013 (el promedio de la Unión Europea es de 40\%). Al mismo tiempo, se multiplicó la inversión nacional en obras públicas.

Esos recursos se orientaron sobre todo a la integración de los 20 millones de excluidos y al fortalecimiento de la infraestructura (en especial, la energía y los transportes).

Para lograr esos resultados, se ejecutaron gradualmente actos políticos, que se sintetizan en el cuadro 3, agrupados por actos de defensa de la soberanía nacional; de inclusión social; de política económica; planes de obras públicas; y educación, cultura, investigación científica y tecnología.

\begin{tabular}{|c|c|c|}
\hline & Actos políticos & Naturaleza de cada acto \\
\hline \multicolumn{3}{|c|}{ Defensa de la soberanía nacional } \\
\hline 1 & $\begin{array}{l}\text { Reestructuración de la deuda } \\
\text { externa }\end{array}$ & $\begin{array}{l}\text { Renegociación de la deuda externa con una quita de } \\
\text { alrededor de } 66 \% \text { y alargamiento de los plazos; } \\
\text { aceptada por } 92.4 \% \text { de los acreedores. }\end{array}$ \\
\hline 2 & $\begin{array}{l}\text { El FMI no interviene más en la } \\
\text { política económica argentina }\end{array}$ & $\begin{array}{l}\text { Desligamiento del FMI con el pago de toda la deuda con } \\
\text { el FMI. }\end{array}$ \\
\hline 3 & Desendeudamiento & $\begin{array}{l}\text { La deuda del sector público nacional en } 2002 \text { era el } \\
164 \% \text { del PIB; y en } 2013 \text { de } 39.5 \% \text {. La deuda pública } \\
\text { externa en } 2002 \text { era } 95 \% \text { del PIB; y en } 2013 \text { era del } \\
11.6 \% \text {. }\end{array}$ \\
\hline 4 & $\begin{array}{l}\text { Política internacional } \\
\text { independiente }\end{array}$ & $\begin{array}{l}\text { Se recupera soberanía nacional. Se implanta la Unión } \\
\text { de Naciones Suramericanas (Unasur), como mecanismo } \\
\text { político. Se crea la Comunidad de Estados Latinoameri- } \\
\text { canos y Caribeños (CELAC) como un bloque geopolítico. } \\
\text { Se veta el Área de Libre Comercio de las Américas } \\
\text { (ALCA). }\end{array}$ \\
\hline 5 & $\begin{array}{l}\text { Estatizaciones: correo, agua, } \\
\text { trenes, línea aérea }\end{array}$ & $\begin{array}{l}\text { Recuperación para el Estado de varios servicios } \\
\text { públicos esenciales. }\end{array}$ \\
\hline 6 & $\begin{array}{l}\text { Recuperación de la soberanía } \\
\text { nacional sobre Yacimientos } \\
\text { Petrolíferos Fiscales (YPF) }\end{array}$ & $\begin{array}{l}\text { Se recupera la mayoría accionaria sobre YPF (petróleo y } \\
\text { gas). Fuerte aumento de las inversiones. }\end{array}$ \\
\hline 7 & Ley de tierras rurales & $\begin{array}{l}\text { Pone un tope de } 15 \% \text { de la tierra de propiedad extran- } \\
\text { jera, a nivel nacional, provincial, departamental y por } \\
\text { nacionalidad. }\end{array}$ \\
\hline & & Inclusión social \\
\hline
\end{tabular}


Estatuto del peón rural

Más y mejores empleos

Aumento salarial y Asignación Universal por Hijo (AUH)

Desmonopolización de la fabri-

17
Ley de medios audiovisuales cación de papel para diarios

Castigo a crímenes de lesa humanidad

Plena vigencia del Estado de derecho

16 Tipo de cambio con flotación administrada

Política antiinflacionaria no recesiva
Entre 2002 y 2014, la participación de los asalariados en el ingreso creció de 34 a 51\% del PIB. Coeficiente de Gini: 2003: 0.534; 2015: 0.420. Desde 2003 hasta 2014 se crearon 5 millones de nuevos empleos. En 2014 el desempleo era de $7.2 \%$ (en 2002, era del 21.5\%). En 2012 el empleo no registrado era de $33 \%$; en 2003 , de $49 \%$.

En diciembre de 2006 se recuperó el nivel de salarios reales anterior a la crisis de 2002. En 2013 se aprobaron 1600 convenios colectivos de trabajo entre asalariados y empresarios (en 2002 eran 200). La AUH cubre a 3.3 millones de niños y jóvenes, hijos de desocupados y de trabajadores no registrados.

Incorpora al peón rural a la ley de contrato de trabajo. Crea el Registro Nacional de Trabajo y Empleo Agrario, fija salarios mínimos, jornada de 8 horas y descanso semanal.

Se reestatizó el sistema jubilatorio. Existen aumentos de jubilaciones en marzo y septiembre de cada año. Hasta 2003 y durante 10 años, la jubilación estuvo congelada. Cubre $97 \%$ de los posibles jubilados (en 2003 era 65\%). Se incorporaron al sistema 2.9 millones de personas que no tenían aportes suficientes.

\section{Derechos humanos}

Juicio a los responsables: 1013 procesados, 439 condenados, 40 absueltos. El resto en juicio.

Son respetados todos los derechos humanos, civiles y políticos. No represión a protestas sociales y políticas.

Pone límites (generosos) al número de radios y canales de televisión que pueden estar en manos de un solo dueño. Prevé distribuir las señales entre el sector privado comercial, el sector privado sin fines de lucro y el sector público. Cuando se aplique integralmente, terminará el oligopolio de la televisión y la radio.

La dictadura militar forzó la cesión de Papel Prensa (que monopoliza la fabricación de papel para diarios) a los diarios Clarín, La Nación y La Razón. La ley 26736 (diciembre de 2011) declaró de interés público la fabricación, comercialización y distribución de pasta celulosa y papel para diarios. Existe un juicio penal por los posibles delitos cometidos durante la cesión.

\section{Política económica}

Se abandonó el tipo de cambio "superfijo" de la convertibilidad y se pasó a uno administrado.

Procura controlar la inflación mediante el estímulo de la oferta antes que con la depresión de la demanda. Programas para combatir la suba arbitraria de precios. 
Política fiscal contracíclica cia, Tecnología e Inno-vación Productiva. Fuerte asignación de recursos
Entre 2003 y 2010 todos los años arrojaron superávits financieros salvo en 2009 (año de recesión). Desde 2011 se procura compensar la menor tasa de crecimiento con transferencias sociales e inversión pública. El saldo fiscal financiero del Sector Público Nacional no Financiero pasó a ser deficitario pero moderado (-2.5\% del PIB en 2014).

La recuperación del rol del Estado en la economía se apoyó en un aumento de los ingresos fiscales, dando una mayor participación a los impuestos progresivos (incluyendo los que gravan a las exportaciones primarias), aunque en la estructura tributaria todavía predominan los impuestos indirectos.

Sanción de la Carta Orgánica del Banco Central, que además de la estabilidad monetaria debe promover "la estabilidad financiera, el empleo y el desarrollo económico con equidad social".

La ley 26.683 (junio de 2011) impone penas a quienes pongan en circulación en el mercado bienes provenientes de un ilícito penal. La ley 24.769 (enero de 1997) impone penas a los evasores fiscales.

La ley 26.831 (noviembre de 2012) regula los sujetos y valores negociables comprendidos dentro del mercado de capitales.

\section{Planes de obras públicas}

Desde 2003 a 2013, las mejoras habitacionales y viviendas nuevas se acercan a 1 millón. Se incorporaron 8700 megavatios de generación eléctrica y 4200 km de líneas de extra alta tensión. Se construyeron 2500 km de gasoductos troncales.

La represa de Yacyretá alcanzó su cota máxima de 83 metros.

Se rehabilitaron los servicios de ferrocarriles de pasajeros del Gran Buenos Aires y se restablecen y amplían progresivamente los servicios de pasajeros y de carga del interior.

Educación, cultura y tecnología

Existen 53 universidades públicas (que son gratuitas; reúnen $80 \%$ del total nacional de estudiantes), 49 privadas y 7 institutos universitarios estatales. Desde 2003 se crearon 9 nuevas universidades estatales. Se construyeron 2000 escuelas primarias.

Repatriación de científicos. Programa de energía nuclear: puesta en marcha de la central nuclear Atucha I. Construcción del reactor nuclear de baja potencia (Carem). Comienzo de la construcción de dos nuevas centrales nucleares. Financiamiento de múltiples investigaciones a universidades. 
La empresa estatal INVAP construye satélites de comunicaciones.

Se restableció la enseñanza técnica, que había sido destruida.

Tiene por objeto el fomento de la actividad musical en general y la nacional en particular, Crea el Instituto Nacional de la Música y Centros de Producción Musical. Establece incentivos.

Ahora todos pueden ver todo el fútbol de primera división por la TV abierta gratuita. Antes, sólo los que la pagaban (caro).

\section{Las ideas políticas}

El modelo de desarrollo económico con inclusión social se realizó en un contexto de mejor distribución de la riqueza, la palabra y el conocimiento. Existió un respeto irrestricto por los derechos humanos. No se reprimieron las protestas sociales y políticas. Se llevó a juicio penal a los responsables de crímenes de lesa humanidad cometidos durante la última dictadura militar. El número de acusados y condenados figura en el punto 12 del cuadro 3.

Desde 2003 funciona con plenitud la democracia y se implantaron elecciones universales y obligatorias para elegir los candidatos de los partidos políticos. En cuanto a la información pública, se sancionó una ley de regulación de los medios de comunicación audiovisual que termine con el oligopolio de los medios hegemónicos; su aplicación plena se retarda por los recursos judiciales de impugnación, que ya llevan cinco años de duración.

El criterio para encarar los problemas complejos se basa en la convicción de que deben politizarse porque las soluciones no son técnicas, como puede serlo su instrumentación. Frente a temas difíciles y trascendentes, lo primero que se hace es sacarlos del plano técnico y llevarlo al político. En seguida, se analiza cuál es el margen de maniobra existente; y si no se tuviera suficiente poder para lograr la solución deseada, se procura generar nuevo poder. Cuando se logra una relación de fuerzas favorable, recién entonces se aplican los actos de gobierno deseados. Es el criterio utilizado en la reforma del régimen de jubilaciones, en la empresa Yacimientos Petrolíferos Fiscales, en el servicio de agua y cloacas (en todos estos casos se restableció la propiedad estatal) y con el litigio con los fondos buitre.

\section{La economía} ción de la política económica en tres áreas fundamentales: una es la recuperación del Estado como instrumento del desarrollo; la segunda es el combate contra la hegemonía del sector financiero y de la lógica rentística; la tercera es la redistribución del ingreso como motor del crecimiento con inclusión social. Tres actos políticos originales marcaron esta orientación de fondo: la renegociación de la deuda externa, la reforma total del régimen de previsión social y una política activa de generación de empleo formal, recuperación salarial y expansión del gasto social. 
El primer acto fue la renegociación de la deuda externa, que era de pago imposible y que trababa todo el funcionamiento económico.

El neoliberalismo comenzado en 1976, que dio un bienestar transitorio a las clases media y alta, se financió con un descomunal endeudamiento externo. Este proceso empezó con la dictadura militar entre 1976 y 1983, y se retomó con los gobiernos de Menem y De la Rúa entre 1989 y 2001. La apertura irrestricta comercial y a los flujos de capitales, combinada con las políticas antiinflacionarias basadas en la apreciación real del peso, incrementaron la deuda pública externa de 7 mil millones de dólares a 88 mil millones entre 1976 y 2001; la deuda externa del sector privado creció de 3000 a 78000 millones de dólares, pero más aumentaron sus saldos no declarados en el exterior. Estas políticas se derrumbaron cuando se cerró el crédito externo. Su caída forzó a emitir bonos públicos por otros 47000 millones de dólares, para evitar que colapsara el sistema financiero local.

El gobierno del Presidente Néstor Kirchner renegoció una parte subs-

El neoliberalismo tancial de la deuda que había entrado en default en diciembre de 2001 comenzado en (82 000 millones de dólares), y en marzo de 2005 cerró el acuerdo con la 1976, que dio un gran mayoría de los acreedores, por el cual $76 \%$ de esa deuda se reesbienestar transitorio tructuró con una quita de $66 \%$ y un alargamiento importante de los plazos a las clases media de pago. En 2010 se reabrió la posibilidad de canjear deuda en default por y alta se financió nuevos títulos, se llevó el monto reestructurado a $92.4 \%$ de los bonistas, con un descomunal con las mismas condiciones de la reestructuración de 2005. Se obtuvo endeudamiento una quita inusual en las renegociaciones de la deuda.

externo Gracias a esa restructuración, a la recuperación del crecimiento económico, a la progresiva apreciación real de la moneda nacional (desde niveles anormalmente deprimidos tras la mega-devaluación de 2002) y a la mejoría en los balances fiscal y de comercio exterior, el peso de la deuda sobre el PIB cayó de manera sustancial. En 2002, el monto de la deuda (externa e interna) del sector público nacional equivalía a $164.4 \%$ del PIB; a mediados de 2014 había disminuido a $42.8 \%$ del PIB. Si se resta de ese monto la deuda con diversos organismos del propio sector público nacional, la deuda pública neta se redujo a $18 \%$ del PIB. ${ }^{4}$ La mayor parte de esta reducción correspondió a la deuda pública externa neta, que entre 2002 y 2013 disminuyó de 95.0 a 11.6\% del PIB (fuente: Ministerio de Economía y Finanzas Públicas).

\footnotetext{
@ El segundo acto fue la reforma de la previsión social

Durante el auge neoliberal, se privatizó el sistema jubilatorio, mediante la sustitución del sistema público de reparto, por el privado por capitalización. Esta reforma que supuestamente desarrollaría el mercado de capitales, impulsaría la inversión y mejoraría las jubilaciones, no cumplió con ninguna de esas promesas. Fue un brillante negocio

La deuda pública neta corresponde a la deuda del sector público nacional con el sector privado, organismos multilaterales y bilaterales y países extranjeros. No se computan aquí los bonos de deuda no presentados para su reestructuración; si se los incluyeran, la deuda pública externa se elevaría a $18.2 \%$ del PIB.
} 
para el sector financiero, ya que las Administradoras de Fondos de Jubilaciones y Pensiones (AFJP) cobraban nada menos que el 36\% de los aportes como comisión para gestionar el sistema. Pero ese régimen no era sostenible, ya que sólo aportaba $39 \%$ de los afiliados a las AFJP, por lo que el Estado se vería obligado a hacerse cargo en el futuro de las jubilaciones mínimas para la gran mayoría de la población. Mientras tanto, debía seguir pagando las jubilaciones sin recibir los aportes jubilatorios, lo que generaba un costo fiscal importante. La reimplantación del sistema público de reparto permitió mejorar la cobertura del sistema previsional, que hoy abarca virtualmente a todas las personas en edad de jubilarse, y aumentar progresivamente el valor de las pensiones y jubilaciones.

La tercera política consistió en el mejoramiento de la cantidad y calidad de los empleos y de los salarios; y en la redistribución del ingreso mediante transferencias sociales, en especial la asignación universal por hijo, subsidios para los jóvenes que quieran retomar o concluir sus estudios y subsidios para la vivienda.

El gobierno revitalizó el sistema de negociaciones paritarias entre trabajadores y empleadores, y mejoró significativamente el salario mínimo (cuando el desempleo era todavía elevado, determinó por decreto mejoras salariales generales). En los años de recesión, tomó medidas para evitar la destrucción de empleos. Estas medidas permitieron una fuerte reducción de los índices de pobreza y en especial de indigencia, ya que sectores de la población que anteriormente no tenían ingreso fijo ni cobertura social y de salud, pasaron a tenerlos. La política de inclusión no solamente tiene un fuerte impacto social, sino que ha procurado hacer de la demanda popular un motor de crecimiento del producto y de la inversión.

\section{Dificultades y obstáculos}

De esta enumeración de logros no debe deducirse que se transitó por un camino despejado. Por el contrario, los obstáculos fueron importantes y frustraron o retardaron la ejecución de algunos actos de gobierno esenciales. Peor aún: existieron tentativas de derrocar al gobierno por "golpes de mercado"5 (hubo diez corridas sobre el dólar); y grupos empresarios extranjeros y nacionales provocaron una devaluación en enero de 2014. Es obvio que las dificultades son directamente proporcionales a la magnitud de los intereses que se afectan. En varios casos fundamentales -por ejemplo, la estatización del régimen de jubilaciones, la mayoría estatal en Yacimientos Petrolíferos Fiscales (YPF), la ley de regulación de los medios de comunicación audiovisual- el gobierno debió generar el poder político necesario para aprobarlas y ejecutarlas.

Los principales obstáculos con los que se enfrentó el gobierno fueron: en lo social, la existencia de una burguesía que en gran medida carece de un sentido nacional; en lo económico, la inflación y la extorsión de los fondos buitre; y en lo institucional, la acción política de un grupo de jueces y continuas campañas negativas de los oligopolios de prensa, radio y televisión.

Como en la Argentina ya no son viables los golpes de Estado militares, algunos grupos corporativos recurren a "golpe de mercado", como lo hicieron cuando obligaron a renunciar al Presidente Raúl Alfonsín (1989). 
Tal vez el principal problema sea que no existe una burguesía nacional, al menos no lo suficientemente fuerte entre las empresas principales. En 2013, las 500 mayores empresas generaban $34 \%$ del valor agregado de sus sectores en el total del país; y dentro de ellas, las que tienen más de $10 \%$ de capital extranjero eran $60 \%$ en cuanto al número, generaban $79 \%$ del valor agregado y $81 \%$ de las utilidades de esas 500 empresas. Pero la mayor dificultad tal vez no sea que a las empresas extranjeras no les importe el sentido nacional argentino; es natural que así sea. El problema sustancial es que un grupo importante del resto de las empresas, que son nacionales grandes, aunque también algunas medianas y pequeñas, tampoco ha actuado históricamente como

El problema sustancial es que un grupo importante del resto de las empresas que son nacionales grandes, tampoco ha actuado históricamente como defensor del interés nacional argentino defensor del interés nacional argentino. ${ }^{6}$ En ocasiones, parecen incluso ignorar sus propios intereses de largo plazo, tienden a buscar rentas antes que a invertir, y se oponen a políticas de fortalecimiento del mercado interno que en definitiva les genera más beneficios.

El segundo problema (o desafío) social es el planteado por un amplio grupo social que ascendió socialmente y que duplicó el número de integrantes de la clase media, según un estudio del Banco Mundial. Se trata de grupos heterogéneos: desde los tradicionales profesionales autónomos y pequeños empresarios, hasta los obreros calificados que ascendieron, hay una enorme gama de valores, modos de vida, intereses, ideas y costumbres.

Muchos de ellos podrían no reconocer que su ascenso social se debe a políticas públicas activas, creer en la irreversibilidad de los cambios que los favorecieron desde 2003 y adoptar posiciones políticas conservadoras. Ya algunos se sienten instalados en una clase media que los incita a olvidarse de su pasado reciente, en el que sufrieron privaciones. Existe el riesgo (alentado por la mayoría de los medios de comunicación masivos) que quieran parecerse a las clases altas; pero como no pueden alcanzar sus pautas de consumo, que traten de imitarlos a través de sus opiniones reaccionarias. perdió un referéndum y renunció, le dijo a su Primer Ministro Michel Debré: "y bien, así es: hemos vencido a los alemanes, hemos aplastado a Vichy, hemos impedido a los comunistas que tomen el poder y a la OAS que destruya a la República. No hemos podido enseñarle a la burguesía el sentido nacional (Michel Debré, Entretiens avec le général De Gaulle, 1961-1969, Albin Michel, París, 1993, p. 207). 
Problemas económicos

\section{La inflación}

La situación actual muestra una tasa de suba de precios al consumidor de entre 20 y $25 \%$ anual, con tendencia a la baja gradual. A diferencia de los episodios de rápida inflación que sufrió la Argentina repetidas veces, no se trata ahora de una inflación "de crisis", generada por desequilibrios incontrolables en las cuentas externas y fiscales, y en la cual se producía un círculo vicioso de devaluación, aumento de precios y emisión masiva del Banco Central para financiar al gobierno y a un sector financiero con riesgo de colapsar. La inflación que vivimos se debe más bien a la ausencia de crisis, ya que la demanda es lo bastante fuerte y sostenida como para que los empresarios puedan aumentar sus precios sin perder ventas, y el desempleo es lo bastante bajo como para que los asalariados logren mejoras salariales que compensen, muchas veces con creces, tales aumentos de precios.

¿Qué corresponde hacer ante tal situación? Existen dos respuestas

El modelo de desarrollo con inclusión social afirma que una inflación baja no es el único objetivo económico, ni el principal; lo esencial es el crecimiento, la distribución del ingreso y la reindustrialización básicas: la neoliberal consiste en disminuir la demanda; para eso, se provoca una recesión, con medidas tales como la rebaja de los salarios reales, de las jubilaciones y del gasto público; se aprecia la moneda nacional y se eleva la tasa de interés; con este enfoque, el Banco Central tendría como eje la aplicación de las "metas de inflación", manejadas a través de las tasas de interés. De tal modo, se sacrifican el empleo y la producción, en aras de un objetivo de estabilidad nominal sacralizado; los ganadores serían los especuladores financieros y los perdedores los asalariados.

Por el contrario, el modelo de desarrollo con inclusión social afirma que una inflación baja no es el único objetivo económico, ni el principal: hay que controlar la inflación, pero lo esencial es el crecimiento, la distribución del ingreso y la reindustrialización. La inflación debe ser ubicada en su justo lugar y dimensión: no es el eje de una política, sino un obstáculo que debe ser controlado y disuelto. $Y$ los instrumentos para hacerlo deben ser consistentes con el desarrollo económico y social: es preciso regular el aumento de la demanda, pero en vez de bajarla, hay que aumentar la oferta.

Otro factor importante es reducir las expectativas de inflación. Tras varios años con una inflación de dos dígitos, ese aumento de precios puede desencadenar expectativas de nuevas alzas de precios y comportamientos que terminen generalizando esas subas, sea porque más empresarios estiman que tienen que «cubrirse» frente a una hipotética inflación, o porque se desate una carrera entre precios y salarios. No es fácil revertir ese proceso, y en la medida en que el gobierno no ha querido recurrir a recetas recesivas, se aplica una estrategia gradualista, apoyada en acuerdos salariales que no incluyan aumentos excesivos y en la concertación con productores y cadenas de comercialización. También es importante brindar un marco macroeconómico consistente con la desaceleración paulatina de precios. 
Los fondos buitre son grupos financieros que compraron títulos de deuda argentina en default y en vez de presentarlos a los canjes, litigaron contra el país para cobrar la totalidad del valor nominal más intereses y punitorios, intentando repetidamente (pero sin éxito) embargar activos del Estado argentino en el exterior. Tras varios años, obtuvieron una sentencia favorable del Poder Judicial de Estados Unidos, con una interpretación sin precedentes e irracional de la cláusula paripassu. En vez de entenderla como un principio general por el que todos los bonistas deben acceder al mismo trato equitativo e imparcial (por ejemplo, que la proporción de la quita y demás condiciones deben ser iguales para todos ellos), el juez Thomas Griesa de Nueva York resolvió que esa cláusula significaba que no podía pagarse la deuda reestructurada si no se pagaba antes la deuda sin reestructurar, sin quitas ni plazos, al pequeño grupo que no aceptó la reestructuración.

En un caso análogo, la Corte Suprema de Justicia de la Argentina resolvió que una sentencia extranjera análoga a la de ese juez de Nueva York, no puede aplicarse porque es violatoria del orden público del derecho argentino (Claren Corporation c/ Estado Nacional, 6 de marzo de 2014). Otras violaciones legales son la prohibición de cobro a $92.4 \%$ de los bonistas, que no son parte de ese juicio, y que en su mayoría están fuera de la jurisdicción del juez de Nueva York; y la tentativa de delito de usura cometida por los fondos buitre. Este conjunto de incongruencias puede entorpecer futuras restructuraciones.

Frente a las contradicciones expuestas, ¿cuál sentencia debe prevalecer: la del tribunal argentino o la del estadounidense? Para estos casos, el derecho internacional establece el arbitraje de la Corte Internacional de Justicia de La Haya, pero los países involucrados deben dar su consentimiento; en este caso, la Argentina pidió ese arbitraje y Estados Unidos no lo aceptó.

En el plano moral y práctico, para la Argentina la alternativa se plantea entre violar el orden público nacional, quebrantar la reestructuración de la deuda externa de 2005 y 2010 con $92.4 \%$ de los bonistas, y contraer una deuda imposible de pagar; o pagar a los fondos buitre en las mismas condiciones que a los demás acreedores, lo cual, considerando el bajo precio que pagaron, les redituaría una tasa de beneficios de $300 \%$ en 5 años (los fondos buitres pretenden un beneficio de 1600\%). Mientras tanto, el gobierno propone canales alternativos para que los poseedores de bonos reestructurados puedan seguir recibiendo los pagos que hace la Argentina, pese a la prohibición que quiere imponer el juez norteamericano.

Desde el punto de vista estadounidense, tal vez la disyuntiva oscile entre la defensa del interés nacional, al que le conviene facilitar la reestructuración de las deudas externas de otros países y fortalecer a la plaza financiera de Nueva York; o satisfacer la avidez de los fondos buitre, que son grandes financiadores de las campañas electorales.

En el fondo, se plantea un problema de terrorismo financiero, pues los fondos buitre pretenden que caigan las renegociaciones de la deuda de 2005 y 2010, toman 
como rehenes a los bonistas que aceptaron el canje, y operan desde guaridas que son los paraísos fiscales, donde no hay ley ni control. La Asamblea General de las Naciones Unidas, a propuesta de la Argentina, aprobó la decisión de elaborar "un marco jurídico multilateral para los procesos de reestructuración de la deuda soberana".

\section{Interferencia de un grupo de jueces}

En todas las épocas, jueces de convicciones y lazos conservadores o reaccionarios, ubicados en posiciones estratégicas, interfirieron en las decisiones políticas de los gobiernos. El ejemplo clásico es la acción de la Suprema Corte de Estados Unidos, que frenó y estuvo a punto de impedir la política de New Deal del Presidente Roosevelt.

En la Argentina actual, algunos jueces utilizan los recursos de amparo y de inconstitucionalidad; para frenar decisiones del Congreso y del Poder Ejecutivo Nacional. Como su argumentación es débil, recurren a medidas precautorias, que paralizan la ejecución de actos de gobierno, sin entrar al fondo de la cuestión. Así, un juez de primera instancia impide actos importantes del Poder Ejecutivo -entre otros, el uso de las reservas del Banco Central y la ley de regulación de los servicios de comunicación audiovisual- con inconstitucionalidades que después de un tiempo son revocadas por el propio Poder Judicial; pero ya se ha logrado el objetivo, que era trabar una acción del gobierno. Por ejemplo, por aplicación de la ley de servicios de comunicación audiovisual sancionada en octubre de 2009, el oligopolio del grupo Clarín (radio y televisión) debería vender numerosas emisoras de televisión y radio; pero hasta ahora esa venta está trabada por recursos judiciales.

\section{El futuro ${ }^{7}$} lesa humanidad, que dejaron decenas de miles de desaparecidos, muertos, torturados y exilados. Los gobiernos electos que continuaron las políticas neoliberales desvirtuaron el sistema democrático al concentrar el poder real en el establishment local e internacional. En cambio, las transformaciones profundas generadas por el actual modelo argentino comenzado en 2003 se realizaron en paz y con la plena vigencia del estado de derecho y las garantías individuales y políticas. Se hicieron también con la intención de construir una sociedad y una economía inclusivas, sustento vivo de una democracia plena y participativa. Los resultados de ambos modelos, sintetizados con algunos indicadores clave en el cuadro 2, muestran que no es cierto que para desarrollarse haya que resignar la igualdad y la soberanía (tanto la soberanía del Estado respecto de los intereses extranjeros como la soberanía popular dentro de ese Estado).

Queda claro que este artículo no propone la aplicación de la política económica argentina desde 2003, a países que sufren la actual crisis financiera internacional. La

Para un desarrollo más amplio, véase Alfredo Eric Calcagno y Alfredo Fernando Calcagno, El Universo Neoliberal. Recuento de sus lugares comunes, en especial el Epílogo de Eric Calcagno, Ediciones Akal, Madrid, 2015. 
Todos los gobiernos populares elaboran planes de desarrollo económico con inclusión social

situación de cada país es única y son sus pueblos y dirigentes quienes tienen que resolverlas. Sin embargo, en la raíz de la crisis global actual (crisis que es económica, social y política) existen los tres problemas centrales con los que ha lidiado la Argentina desde 2003: cómo desbaratar la hegemonía del sector financiero globalizado y de sus agentes locales; cómo restablecer la potestad soberana del Estado para cumplir con su rol histórico de impulsar un desarrollo incluyente y sostenible; y cómo redistribuir la riqueza, el conocimiento y la palabra para dar el sustento económico, político y social a ese proceso.

Todos los gobiernos populares elaboran planes de desarrollo económico con inclusión social. El problema es que, sin experiencias duraderas, quedan en la elaboración teórica: se profundiza en el "qué", pero no existe experiencia para determinar el "cómo"; en este breve artículo procuré, desde mi punto de vista, describir de qué modo y cómo se intentó lograrlo durante doce años.

Tal vez este artículo sea útil como insumo en un análisis comparativo de las diversas experiencias latinoamericanas en lo que va del siglo XXI. Si bien no sabemos qué ocurrirá en el largo plazo, por lo menos aporta información para analizar el mediano plazo. Sobre todo, esta política económica ha sido una prueba tangible de que no existen ni pensamientos ni soluciones únicos. A las políticas económicas las construyen los países, sus gobiernos y los actores políticos, económicos y sociales.

En síntesis, este relato se limita a sintetizar la experiencia positiva de A las políticas un país que salió de la crisis porque reasumió su soberanía y aplicó una económicas las política económica que está en las antípodas de la del FMI. Sin duda que construyen los países, como todo proceso histórico transformador tiene problemas, contradicsus gobiernos y los ciones y contradictores, tanto internos como externos, y como en todo actores políticos, proceso democrático, en el futuro se plantearán nuevos problemas y nueeconómicos y sociales vas soluciones. Pero lo ya alcanzado establece una base material, social y cultural que hace muy difícil el regreso a un sistema de inequidad y sometimiento, que en todo caso ya no podrá ser presentado como el único posible.

\section{Bibliografía}

CALCAGno, Alfredo Eric y Alfredo Fernando Calcagno, El Universo Neoliberal. Recuento de sus lugares comunes, en especial el Epílogo de Eric Calcagno, Ediciones Akal, Madrid, 2015. 